\title{
Expanding research views
}

\author{
Regions most affected by climate change are not always the areas that receive the most attention. Africa \\ is one example of a region that highlights the need for research in more difficult locations.
}

Shifting rainfall patterns, extreme heat and the El Niño event of 2015-2016 have left East Africa on the brink of a humanitarian crisis. March 2017 saw urgent appeals for aid as people face on-going food shortages and starvation across the region, with Somalia the worst affected with about six million at risk - about half the population ${ }^{1}$. Vulnerable areas in southern Ethiopia, northern Kenya, and the Republic of South Sudan raises the total number at risk to 16 million people. The Republic of South Sudan has declared an official famine, the first country to do so in five years, whilst other nations are declaring national emergencies, including neighbouring countries currently less affected ${ }^{2}$.

This region has two rain seasons per year, in the spring and autumn. With heavy reliance on rainfed agriculture, drought, crop failure, and consequential food shortages and famine in East Africa are becoming all too common. "In Africa many communities observe alteration of the rainy season, describing it as shorter, shifted, and interrupted with dry spells" (Savo et al.; ref. 3). The current drought, which is the third in the region in the last 25 years, is the result of light spring rains and failed autumn rains in 2016 - this year's spring rains are not looking promising to break the drought, with projections of light rains.

Climate change is contributing to the increased frequency of drought in the area, with occurrence now almost annual. Increases in heat and changes in rainfall patterns require smallholders to adapt to ensure survival but limited information is available 4 . On-the-ground data is limited in many of these countries, indicating there may be a bias in where climate change research is carried out. In a recent study, Cullen Hendrix analysed scholarly attention on climate change and Africa to show that the streetlight effect - observational bias created by only looking where it is easiest - can be seen for climate change research in Africa ${ }^{5}$. South Africa and Kenya, with a combined population of 99 million and covering around $6 \%$ of African land mass, are shown to account for a similar amount of scholarly attention as 29 other African countries, with population of 280 million and $44 \%$ of the land mass. The results of the study show that published climate research is more likely to be conducted in countries which are former

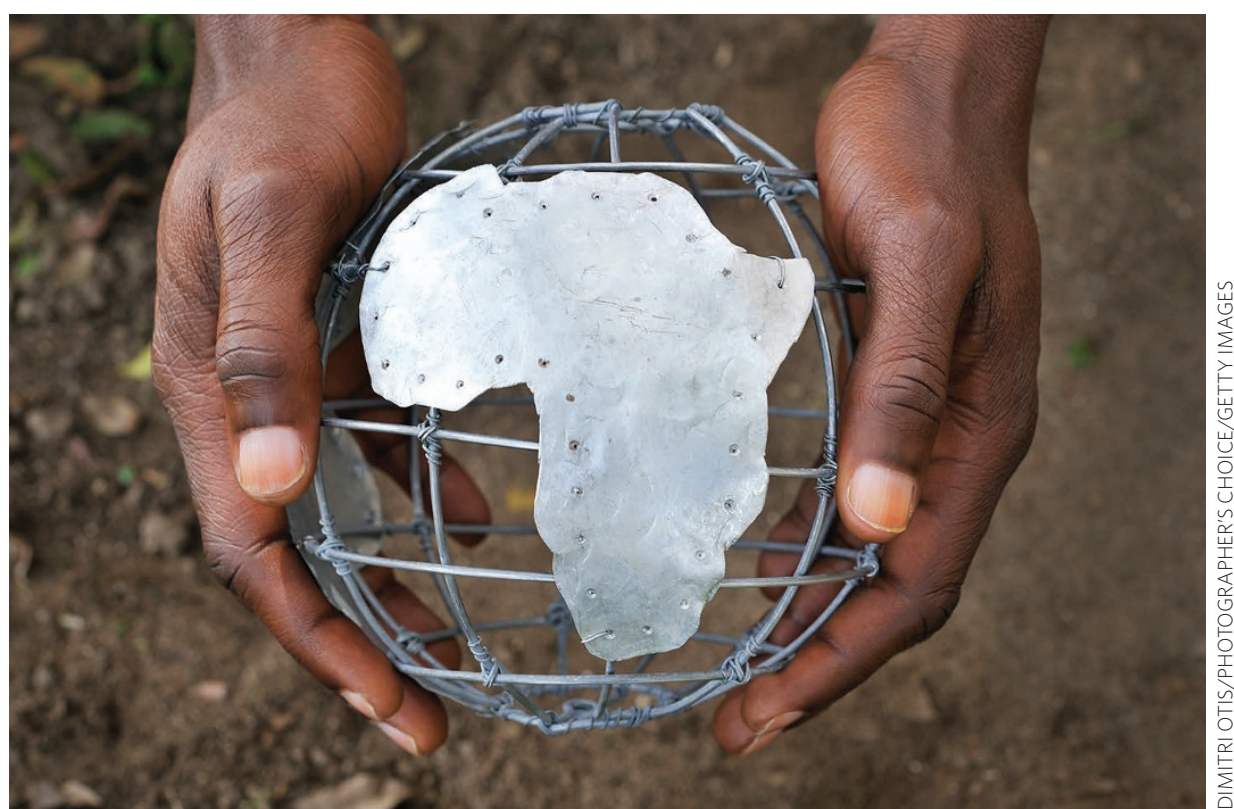

British colonies, have protection of civil liberties and stable political institutions. This may be a result of much of that research being funded and conducted by non-Africans.

Nature Climate Change is one of the three journals analysed in the study and the results of the study are, unfortunately, not that surprising. We have had editorial discussions on how to identify and engage with researchers and practitioners and this is an on-going challenge but a goal that we will keep working towards. We acknowledge that, as in the climate change literature in general, there is a need to do more to have coverage of and information from around the world.

Research shouldn't just be done in locations that are easily accessible or familiar, but rather where there is the greatest need. What is needed is research that informs policy, at all levels of governance, as well as providing climate information that helps adaptation, for example, the smallholder looking to feed their family. Tapping into local knowledge could highlight where climate change impacts are already being experienced, as illustrated in the metaanalysis of traditional ecological knowledge among subsistence-orientated communities by Valentina Savo and colleagues ${ }^{3}$. This Review gathered observations from 2,230 localities across 137 countries, but there are a number of African countries for which no data was available - the authors note this was "potentially due to a lack of studies, a lack of studies in English, and/or a limited stable population", all issues that were highlighted by Hendrix as obstacles that need to be overcome.

Engaging these communities and encouraging researchers to work in these locations will help, but it is then necessary to make the information available to those who need it. Conveying climate messages through visualization to those who may be most vulnerable and have lower levels of literacy is discussed by Alfons Maes in a Commentary (page 231). It is only through the generation and dissemination of knowledge that together we will be able to prepare for the challenges ahead.

\footnotetext{
References

1. Light, J. 6 million people are at risk of starving in East Africa, and climate change deserves part of the blame. UN Dispatch (9 March 2017).

2. Stark pictures show a ravaged land and desperate people as Somalia and East Africa face new famine. UN Environment (8 March 2017).

3. Savo, V. et al. Nat. Clim. Change 6, 462-473 (2016).

4. Thornton, P. K. \& Herrero, M. Nat. Clim. Change 5, 830-836 (2015).

5. Hendrix, C. S. Global Environ. Change 43, 137-147 (2017).
} 


\section{Correction}

In the Editorial 'Expanding research views'

(Nat. Clim. Change 7, 229; 2017) there was a

typographical error in the spelling of the name

Alfons Maes. This has now been corrected in

the online versions after print 7 April 2017. 